\title{
A PESQUISA COM ACÓRDÃOS NAS CIÊNCIAS SOCIAIS: ALGUMAS REFLEXÕES METODOLÓGICAS
}

\author{
Thiago Coacci ${ }^{1}$
}

\begin{abstract}
RESUMO
0 presente trabalho busca refletir metodologicamente sobre o desenho das pesquisas com acórdãos, respondendo a) o que um bom desenho de pesquisa deve levar em conta; b) como encontrar e escolher um acórdão; c) quais os pontos fortes e fracos de uma pesquisa com acórdãos, o que é perdido e o que capturado pelos acórdãos; e d) quais métodos e técnicas podem ser utilizados nas pesquisas com acórdãos. Para isso o texto se divide em três partes, aborda inicialmente a discussão sobre metodologia da pesquisa nas Ciências Sociais. A segunda parte apresenta de forma simples para não juristas o que é um acórdão, como é estruturado e qual o caminho percorrido até que seja proferido, bem como os pontos fortes e fracos no uso de acórdãos como fontes de dados. Por último, são apresentados alguns exemplos de pesquisas com acórdãos nas Ciências Sociais para ilustrar quais dados podem ser coletados a partir de acórdãos, quais métodos são compatíveis com a escolha do acórdão como fonte e de que forma esses métodos podem ser utilizados.
\end{abstract}

Palavras-Chave: Metodologia da pesquisa. Pesquisa com acórdãos. Sociologia e antropologia jurídica.

Mestrando em Ciência Política pela Universidade Federal de Minas Gerais, Brasil. thiagocoacci@gmail.com. 


\title{
SOCIAL SCIENCES' RESEARCH ON SECOND INSTANCE COURT DECISIONS: SOME METHOLOGICAL REFLECTIONS
}

\begin{abstract}
This paper purports to reflect, from a methodological perspective, on second instance court decisions research framework, answering the following questions: a) what should a good research framework encompass; b) how to find and choose a second instance court decision; c) what are the strengths and weaknesses of a second instance court decision research and what is lost and captured by such decisions; d) which methods and techniques can be used in researches involving second instance court decisions. In order to answer these questions the text is divided in three parts. The first addresses the discussion on research methodology in Social Sciences. The second part explains, in a simple way for non-jurists, what a second instance court decision consists of, how it is structured, what courses of action are taken until it is delivered, and the advantages/disadvantages of their use as data sources. Finally, some examples of second instance court decision researches in Social Sciences are presented so as to illustrate which data can be collected from those decisions, which methods are compatible with the choice of the decision as a source and how such methods can be used.
\end{abstract}

Keywords: Research Methodology. Second instance court decision research. Legal Sociology and Anthropology.

\section{INTRODUÇÃO}

antropóloga e advogada Ana Lúcia Pastore Schritzmeyer, quase dez anos após a
defesa de seu mestrado, foi convidada pelo Instituto Brasileiro de Ciências
Criminais - IBCCRIM a publicar sua dissertação de mestrado em Antropologia Social, intitulada Sortilégio de Saberes: Curandeiros e Juizes nos Tribunais Brasileiros (1900-1990), no formato de um livro, voltado para o público jurídico. À época foi sugerido à pesquisadora que reduzisse ou mesmo suprimisse do livro seu capítulo metodológico. Schritzmeyer não apenas recusou a sugestão, mantendo o capítulo praticamente intacto, como respondeu, inserindo na primeira página desse a seguinte nota de rodapé:

Embora tenham me sugerido que, para esta publicação, eu minimizasse ou mesmo suprimisse este capítulo metodológico, lançando algumas informações anexas, decidi mantê-lo, quase na íntegra, pois considero que, justamente por este livro voltar-se para leitores majoritariamente formados em Direito, é fundamental informar-lhes que a metodologia para cientistas sociais e, especialmente, para antropólogos não é mero apêndice do trabalho 
intelectual, mas constitutiva de seu fazer e determinante em seus resultados, cabendo, portanto, expô-la de modo a legitimar o trabalho e a colocá-lo em condição de ser devidamente avaliado (SCHRITZMEYER, 2004, p. 83-84).

Como a experiência de Schritzmeyer mostra, a preocupação com o rigor metodológico não faz parte do cotidiano de grande parte das pesquisas e das atividades profissionais no Direito. 0 campo jurídico não acompanhou as outras ciências humanas no desenvolvimento e crescimento da pesquisa (NOBRE, 2004). Técnicas de pesquisa social como surveys, grupos focais, etnografias e outras são pouquíssimo conhecidas, a metodologia é tratada como sendo um mero apêndice do trabalho intelectual, quando não é confundida com a normalização. Porém, é preciso levar a metodologia a sério, pois como Lima (2012, p. 37) argumenta:

Promover a pesquisa empírica no campo das práticas judiciárias, por exemplo, pode explicitar paradoxos cuidadosamente ocultos, como aqueles que estão presentes no sistema de Justiça criminal, no qual a prática dos atores do sistema está submetida a uma teoria distinta daquela explicitamente proposta pelos livros e ensinada nos cursos jurídicos.

Sendo assim, o presente trabalho busca refletir metodologicamente sobre 0 desenho das pesquisas com acórdãos, respondendo a) o que um bom desenho de pesquisa deve levar em conta; b) como encontrar e escolher um acórdão; c) quais os pontos fortes e fracos de uma pesquisa com acórdãos, o que é perdido e o que capturado pelos acórdãos; e d) quais métodos e técnicas podem ser utilizados nas pesquisas com acórdãos.

Para responder às perguntas, o artigo se estrutura da seguinte maneira, a primeira parte conta com uma breve discussão sobre metodologia da pesquisa nas Ciências Sociais. A segunda parte tenta apresentar, de forma simples para não juristas, o que é um acórdão, como é estruturado e qual o caminho percorrido até que seja proferido, bem como os pontos fortes e fracos no uso desses como fontes de dados. Na terceira parte serão apresentados alguns exemplos de pesquisas com acórdãos nas Ciências Sociais para ilustrar quais dados podem ser coletados a partir de acórdãos, quais métodos são compatíveis com a escolha do acórdão como fonte e de que forma esses métodos podem ser utilizados. Espera-se ao final do texto ter criado um mapa útil para juristas e não juristas se orientarem metodologicamente na pesquisa com acórdãos. 


\section{LEVANDO A METODOlogia A SÉRIO}

0 desenho da pesquisa é um guia que orienta o pesquisador no desenvolvimento de sua pesquisa. Desenhar a pesquisa é pensar em como desenvolver um problema de pesquisa sólido, mobilizar corretamente a teoria, selecionar dados de qualidade e realizar articulações válidas entre dados e teoria (KING; KEOHANE; VERBA, 1994). Mas como fazer isso? Alias, como fazer isso bem?

No ano de 1994, Gary King, Robert Keohane e Sidney Verba publicaram o já tradicional livro Designing Social Inquiry: Scientific Inference In Qualitative Research - doravante referido como DSI. Os autores tinham como central a questão do desenho de pesquisa. Pretendiam com o livro "conectar as tradições do que é convencionalmente denominado pesquisa 'quantitativa' e 'qualitativa' aplicando uma lógica da inferência unificada para as duas." (KING; KEOHANE; VERBA, 1994, p. 3, tradução nossa), argumentando que ambas tradições de pesquisa, no que pese se mostrarem diferentes e as vezes até mesmo em disputa, diferenciam-se em função do estilo e das técnicas, mas compartilham lógica comum que fornece o enquadramento para ambas abordagens.

Para o DSI os estilos das pesquisas quantitativas e qualitativas seriam bem diferentes. As pesquisas quantitativas usariam números e métodos estatísticos, eles tenderiam a mensurar aspectos específicos dos fenômenos para analisá-los; partir dos casos concretos para buscar descrições gerais ou testar hipóteses causais; e buscar realizar medidas e análises que são facilmente replicáveis. Por outro lado, as pesquisas qualitativas possuiriam uma miríade de técnicas (entrevistas, grupos focais e etc.), que, essencialmente, não se baseiam em mensurações numéricas (KING; KEOHANE; VERBA, 1994, p. 4). São comumente ligadas a estudos em profundidade de determinados aspectos, características e significados de um caso, ação e/ou símbolo.

Todavia, para o DSI a pesquisa científica nas Ciências Sociais, seja qualitativa ou quantitativas teria um objetivo comum: a inferência descritiva (que busca descrever, a partir do analisado, o não analisado) ou causal (que busca explicar uma relação de causalidade). A inferência seria, para estes autores, uma das quatro características que constituem uma pesquisa científica. É importante compreender o que os autores chamam de pesquisa científica: King, Keohane e Verba (1994) argumentam que haveria a necessidade de distinguir o que é uma boa pesquisa, para isso utilizam a denominação de científica. As características necessárias para que sejam consideradas boas - logo, científicas - são: a publicidade dos procedimentos; a incerteza das conclusões; a centralidade dos métodos; e a já mencionada, a inferência como objetivo.

As sugestões do DSI são um tanto quanto polêmicas e geraram debates na ciência social americana. Muitas das recomendações como as sobre a incerteza das conclusões que recomenda uma quantificação da probabilidade do erro da pesquisa - e da 
centralidade do método para a ciência - que afirma ser a ciência definida por seu método e não por seus objetos - foram contestadas por autores como Henry Brady e David Collier (2004). Em síntese, estes autores criticam que o DSI impunha uma lógica quantitativa para as pesquisas qualitativas, que não se adéqua. Em função das críticas existentes, sugere-se aqui uma apropriação light das recomendações do DSI, que podem, inclusive, não corresponder à proposição original dos autores. Reinterpretam-se as sugestões de maneira que: (1) a publicidade dos procedimentos signifique uma obrigação de tornar explícito os métodos e o caminho percorrido desde a coleta até a análise dos dados, que permitiria a outros pesquisadores compreender e avaliar melhor 0 trabalho e também reproduzi-lo caso seja útil; (2) a incerteza das conclusões signifique o reconhecimento que a ciência não produz verdades universalmente válidas e acabadas, que todo e qualquer resultado obtido pode eventualmente ser falseado, significa também, o reconhecimento e publicidade dos limites implicados pelo desenho da pesquisa ${ }^{2}$; (3) a centralidade do método, que para King, Keohane e Verba (1994, p. 9) significaria que 0 método é o conteúdo principal da ciência, deve ser reinterpretado como um imperativo de refinamento, de que a utilização de métodos compartilhados de coleta e análise de dados podem gerar uma pesquisa de maior qualidade; (4) a inferência como objetivo da pesquisa social, por sua vez, é um ponto de concordância com os autores do DSI, porém reconhecendo que esse atribui excessiva importância à inferência causal e deixa a inferência descritiva em segundo plano (BRADY; COLLIER, 2004, p. 46), ambas são igualmente relevantes, nem todo trabalho pode ou mesmo deseja trabalhar com relações de causalidade.

Já existe no Brasil uma tradição nas Ciências Sociais em estudar o Direito e 0 Judiciário. Seja por meio de uma etnografia de um tribunal do júri, como a realizada por Schritzmeyer (2007); pela inovadora Cartografia da Justiça no Brasil, realizada por Avritzer et al. (2010); ou por estudos mais institucionais, como aqueles que traçam os perfis dos magistrados de um determinado tribunal. 0 foco aqui, contudo, se dará em uma corrente que vem ganhando forças: a pesquisa com acórdãos.

A pesquisa com acórdãos é uma forma de pesquisa documental. São pesquisas que possuem como fonte principal de dados documentos escritos, oficiais do poder judiciário. Os estudos com acórdãos podem ser classificados nas tipologias de Gerring de Estudos de Casos ou Estudos Cruzados de Casos (Cross Case Studies) ${ }^{3}$. Um estudo de

\footnotetext{
${ }^{2}$ Seguindo a crítica feita por Bartels (2004) presente no Rethinking Social Inquiry, abandona-se aqui a proposta do DSI de tentar mensurar os erros presentes na pesquisa, por compreender que mesmo em pesquisas quantitativas essa mensuração pode não ser realizável.

${ }^{3}$ Diversas metodologias podem ser utilizadas para coletar e analisar os acórdãos, a escolha dos Estudos de Caso e dos Estudos Cruzados de Casos se deu pela flexibilidade ímpar que permite a aplicação em uma gama de diferentes agendas de pesquisa. Todavia, é preciso reconhecer que toda metodologia tem suas limitações e há aqueles casos em que os caminhos traçados aqui não serão especialmente úteis.
} 
caso "pode ser compreendido como o estudo intensivo de um único caso em que 0 propósito do estudo é - ao menos em partes - clarear uma classe maior de casos (uma população)." (GERRING, 2007, p. 20, tradução livre). Nos estudos cruzados de casos, por sua vez, o foco da pesquisa muda de um caso único para uma amostra de casos. Gerring argumenta que quanto mais um caso é estudado de forma intensa, mais esse estudo merece a nomenclatura de estudo de caso; quanto mais se afasta do estudo intensivo e se aproxima de um estudo de determinadas variáveis que perpassam esses vários casos, mais mereceria a nomenclatura de estudo cruzado, sendo níveis diferentes de análise. Uma primeira impressão faz parecer que os primeiros seriam qualitativos, enquanto os segundos, seriam quantitativos, não é verdade. É importante perceber que tanto os estudos de casos quanto os estudos cruzados de casos podem se beneficiar de metodologias quantitativas e qualitativas.

É interessante, ainda, diferenciar o que é um caso, uma observação, uma amostra e a população. Um caso para Gerring (2007) pode ser definido como um fenômeno delimitado no espaço e/ou no tempo. Frequentemente não é possível ter uma delimitação clara nos dois âmbitos, como por exemplo no estudo de um país pode ser difícil delimitar temporalmente seu início e fim, mas é importante que haja alguma delimitação temporal e quando possível alguma espacial. No caso das pesquisas com acórdãos, definir o recorte temporal e espacial, significa, por exemplo, coletar acórdãos julgados entre 1988 e 2000 (recorte temporal) nos tribunais de justiça de Minas Gerais, São Paulo e Rio de Janeiro (recorte espacial).

A observação é a mais básica das unidades de análise nas pesquisas empíricas, e consiste na coleta das informações que interessam em um caso em um dado momento. Cada caso pode conter uma ou mais observações. $\mathrm{Na}$ análise de um país através do tempo, cada ano, por exemplo, poderia constituir uma observação. 0 caso é o mesmo, já as observações múltiplas. Cada observação pode, ainda, conter várias dimensões: as variáveis a serem coletadas a cada observação. É importante que as mesmas variáveis sejam coletadas nas diversas observações a fim de garantir a comparabilidade entre essas. No caso das pesquisas com acórdãos, em que um caso é um julgamento de segunda instância e a fonte de dados é exclusivamente o acórdão do julgamento, é comum que haja apenas uma observação por caso. Todavia é possível realizar mais de uma observação, como na hipótese de uma análise mais profunda que cataloga cada um dos votos como uma observação independente. As variáveis na pesquisa com acórdãos, por sua vez, podem ser diversas, são exemplos dessas: o número do acórdão, 0 voto de cada desembargador, o tipo de recurso, a data do julgamento, o nome e o sexo dos desembargadores, as leis e artigos mencionados, a comarca de origem do processo, 0 assunto, os tipos de argumentos utilizados e as estratégias discursivas empregadas e etc.

0 conjunto de casos coletado e suas observações constituem a amostra. Gerring (2007) advoga que os estudos de casos possuem uma amostra pequena, pois isso facilita 
uma análise aprofundada de cada caso, enquanto os estudos cruzados de casos favoreceriam uma amostra grande, para observar mais amplamente as variações entre os casos. Por último, o conjunto total de casos que poderiam ser coletados é chamado de população ou universo.

Duas grandes perguntas surgem ao se abordar a amostra: qual o tamanho (N) adequado e como selecionar os casos a serem analisados. 0 problema do $\mathrm{N}$ pode ser solucionado a partir de uma reflexão sobre os objetivos e as condições empíricas para a pesquisa. Gerring (2007) argumenta que a escolha por uma amostra grande ou pequena deriva dos objetivos da pesquisa, escolher por um ou outro desenho de pesquisa é um tradeoff entre fraquezas e forças que cada desenho de pesquisa possui. Para auxiliar na escolha, Gerring (2007) levanta dez pontos, dez tradeoffs, feitos ao optar por uma amostra ampla ou pequena.

(1) Se a pesquisa é orientada para a formulação ou teste de hipóteses. A pesquisa com grande amostra é mais eficaz para o teste de uma hipótese, vez que é possível submeter um pequeno número de variáveis ao teste em um número grande de casos, podendo comprovar ou falsificar uma hipótese. Pode-se por exemplo, perguntar se relatoras mulheres são mais favoráveis a punir agressores de violência contra a mulher. Falsificar ou comprovar essa hipótese não depende de um único caso, pois em se tratando de ciências sociais e também de ciências naturais, o caso em análise pode ser uma exceção a regra, sendo mais facilmente realizável em estudos com grande amostra que seja representativa da população. 0 estudo de poucos casos, por sua vez, é mais útil em estágios exploratórios de um assunto. 0 aprofundamento de cada caso permite identificar relações entre um número maior de variáveis, a presença dessas atuando em um mesmo caso pode ser interpretado como um indício de causalidade, útil para a formulação de hipóteses (GERRING, 2007).

(2) Se é priorizada a validade interna ou externa a amostra. Uma amostra pequena tende a não ser representativa da população de casos, dificultando a generalização do conhecimento produzido pelo estudo. Em contrapartida, observar um número grande casos oculta algumas particularidades de cada caso que compõem a amostra, o que faz com que a generalização produzida, não seja um retrato fiel de cada caso, mas uma aproximação confiável. Observar poucos casos garante uma validade interna a amostra maior, a análise realizada será mais fiel a própria amostra, levando em conta as peculiaridades dos casos.

(3) Se deseja explicar mecanismos ou efeitos causais. Os mecanismos causais, ou seja, a forma como opera uma relação de causalidade, o caminho de X a Y, pode ser melhor explicado através de um estudo em profundidade com amostra pequena, enquanto em um trabalho de grande amostra esse fica desfocado, sendo, muitas vezes, levado como pressuposto (GERRING, 2007). Trabalhar com uma quantidade grande de 
casos permite precisar a incerteza da causalidade de uma relação (qual a probabilidade de $\mathrm{Y}$ acontecer, caso X aconteça) e mensurar a magnitude dos efeitos da causalidade (qual a variação esperada em Y, em decorrência de uma variação em X).

(4) Se a dimensão da explicação buscada é horizontal ou vertical. 0 problema da dimensão da explicação é relacionado com o da validade (ponto 2), quanto maior 0 número de casos analisados, mais difícil fica a análise em profundidade de cada caso, por outro lado, maior fica a amplitude da análise. Um estudo sobre o Brasil pode dizer muito pouco sobre a América Latina como um todo, por outro lado, mostrará uma riqueza de aspectos do Brasil que ficariam de lado em um estudo comparativo entre Brasil, México, Argentina, Venezuela e Panamá. É uma escolha entre saber muito sobre pouco ou pouco sobre muito.

(5) Se a população dos casos é heterogênea ou homogênea. A análise de um número grande de casos exige que esses casos sejam muito similares para que se formulem generalizações válidas, de forma contrária não haverá comparabilidade entre os vários casos e as generalizações serão, provavelmente, incorretas. 0 estudo com pequena amostra pode, mais facilmente, lidar com heterogeneidades, uma vez que consegue observar em detalhes as circunstâncias de cada caso que importam a pesquisa. Gerring (2007) afirma que o problema da população heterogênea/homogênea de casos é um tradeoff entre $\mathrm{N}$ (observações) e K (variáveis). Se a cada novo caso adicionado esse oferecer apenas uma nova observação e for necessária, para neutralizar a heterogeneidade, a inclusão de uma nova variável de controle, adicionar um novo caso pode sair muito caro. Agora, se cada novo caso oferecer várias novas observações ou se dispensar a adição de novas variáveis de controle, então a inserção é relativamente fácil e é recomendável um desenho de pesquisa com amostra maior.

(6) Se trabalha com uma relação causal forte ou fraca. Relações causais fracas são difíceis de serem percebidas e corretamente mensuradas em um único caso. Se X tem pouca força para causar Y, os diversos outros fatores que influenciam Y podem levar a uma interpretação errada da relação causal entre X e Y. Ampliar a amostra permite controlar o erro e verificar mais apropriadamente o tipo de relação causal existente entre $\mathrm{X}$ e Y. Por outro lado, se a relação causal é forte e patente, um estudo com grande número de casos se mostra menos útil. Se a copresença de $\mathrm{X}$ e $\mathrm{Y}$ abrange todos os casos, é mais interessante uma pesquisa detalhada de poucos casos para demonstrar como a relação de causalidade opera, ou, ainda, para falsear a causalidade demonstrando que a copresença e a variação dos elementos não passa de uma coincidência e/ou análise espúria.

(7) Se a distribuição de variações úteis a serem analisadas é dispersa em vários casos ou concentrada. As variações úteis são "variações (temporais ou espaciais) em algum um aspecto relevante que dão pistas sobre uma relação causal" (GERRING, 2007, 
p. 56), é alguma variação que torna o caso especialmente interessante para a pesquisa por auxiliar a corroborar ou refutar a hipótese de pesquisa. Ou seja, deve se perguntar se na população de casos, há poucos casos que concentram as variações úteis ou se essas estão dispersas por diversos casos. Na primeira hipótese, os estudos com pequenas amostras são recomendáveis, uma vez que ampliá-la não trará grandes benefícios. 0 estudo detalhado dos casos que concentram as variações é mais recomendado. $\mathrm{Na}$ hipótese destas estarem dispersas, é mais recomendável o uso de uma amostra grande que contemple os vários casos com as variações úteis.

(8) Se a disponibilidade de dados é concentrada ou dispersa. É necessário para desenhar a pesquisa saber minimamente sobre a disponibilidade de informações acerca da população de casos. Se há poucas informações ou ainda se há informações disponíveis sobre poucos casos da população, um desenho de pesquisa de estudo de caso com pequena amostra é mais recomendável. Um estudo com grande amostra nessas condições não é recomendável, pois o estudo se sustentaria quase exclusivamente sobre informações de poucos casos que não necessariamente podem ser generalizadas para os outros. Onde há informações de qualidade dispersas por todos os casos ou para boa quantidade deles, o ganho realizado por uma pesquisa de estudo de caso pode ser pequeno comparado com um estudo cruzado de casos com grande amostra.

Outros fatores como (9) complexidade da relação causal e (10) o estado da arte do assunto a ser pesquisado, como afirma Gerring (2007), podem favorecer e desfavorecer ambos desenhos de pesquisa, não possuindo ligação intrínseca com qualquer dos dois. A discussão apresentada até aqui se encontra sistematizada no Quadro 01.

Quadro 1 - Desenhos de pesquisa com pequenas e grandes amostras

\begin{tabular}{lll} 
& Afinidade & \\
\cline { 2 - 3 } Objetivos da Pesquisa & Amostra Pequena & Grande Amostra \\
1. Hipótese & Formular & Testar \\
2. Validade & Interna & Externa \\
3. Explicação Causal & Mecanismos & Efeitos \\
4. Dimensão da Explicação & Vertical & Horizontal \\
\hline Fatores Empíricos & & \\
5. População de Casos & Heterogênea & Homogênea \\
6. Força Causal & Forte & Fraca
\end{tabular}


7. Dispersão de Variações Úteis Concentrada Dispersa

8. Disponibilidade de Dados Concentrada Dispersa

Fatores Adicionais

9. Complexidade Causal Indeterminada

10. Estado da Arte Indeterminado

Fonte: Gerring (2007, p. 38, tradução do autor).

\section{NA TRILHA DOS ACÓRDÃOS ${ }^{4}$}

0 que é um acórdão, como é estruturado e qual o caminho percorrido até que seja proferido, essas são algumas das perguntas que serão respondidas nessa seção. Para melhor compreender o acórdão é necessário dar um passo atrás e compreender como a justiça no Brasil é organizada.

A organização da justiça brasileira, como prevista na Constituição de 1988, pode ser explicada a partir dos seguintes eixos: a) matéria: justiça comum ou especializada; b) abrangência territorial: justiça federal ou estadual; c) instância: primeira, segunda, especiais (tribunais superiores e supremo tribunal federal).

No que compete às instâncias, o Direito brasileiro possui como princípio o Duplo Grau de Jurisdição, que garante a possibilidade das decisões judiciais serem revistas por magistrados diferentes daquele que proferiu a decisão original. Para a efetivação do referido princípio as justiças se dividem em dois graus ou instâncias. A primeira instância é o local na que os processos se iniciam, as provas são produzidas, as testemunhas são ouvidas, o julgamento é realizado e o cumprimento da sentença será efetivado. A função da primeira instância é cumprida por um juiz singular que acompanhará todo o processo. Já a segunda instância, por sua vez, é o local para a revisão das decisões. Quando uma das partes não está satisfeita com alguma decisão de primeira instância, essa poderá recorrer buscando que a sentença seja alterada ou até mesmo desconstituída, isto é, que a decisão seja decretada nula, deixe de existir no mundo jurídico e que uma nova decisão seja proferida. A função da segunda instância é realizada pelos Tribunais, órgãos colegiados compostos por diversos desembargadores que julgarão, em conjunto, o recurso. Desembargador é o nome que se dá aos juízes de segunda instância. Em sua maioria foram juízes de primeira instância que foram

\footnotetext{
${ }^{4}$ A explicação, presente nessa seção, sobre a organização e o funcionamento da justiça, bem como sobre a estruturação do acórdão se orientam principalmente pela Constituição da República Federativa do Brasil de 1988 e pelos códigos de Processo Civil e Penal brasileiros (Lei 5869/73 e Decreto Lei 3689/41 respectivamente). Dessa maneira, podem não ser adequadas para pesquisas que trabalham com períodos históricos anteriores a 1989 e/ou com outros países (BRASIL, 1941, 1973, 1988).
} 
promovidos por merecimento (reconhecimento da prestação de um trabalho exemplar) ou por antiguidade (tempo na magistratura), mas a Constituição prevê que um quinto dos desembargadores sejam advogados e membros do ministério público com mais de dez anos de atividade jurídica (art. 94) (BRASIL, 1988).

Os recursos são julgados por, no mínimo, três desembargadores, sendo um 0 relator e os outros revisores e/ou vogais. 0 relator é o responsável principal pelo processo, o primeiro a analisá-lo e a proferir sua decisão (também chamada de voto). Os revisores e vogais, apesar de não serem os principais responsáveis pelo processo, participam do julgamento proferindo um voto de mesmo peso que 0 relator. 0 conjunto das três decisões compõe o acórdão.

Há ainda a instância especial, composta pelos Tribunais Superiores (Superior Tribunal de Justiça, Superior Tribunal Militar, Tribunal Superior do Trabalho e Tribunal Superior Eleitoral) e pelo Supremo Tribunal Federal - STF e que atua apenas após o esgotamento das outras instâncias. Em termos estritamente jurídicos, a instância especial não pode ser considerada propriamente uma nova instância (ou ainda terceira/quarta instância), vez que não possui como função principal a reanálise de julgamentos, mas atuam como guardiões da Lei e, no caso do STF, da Constituição. A função dos referidos tribunais, ao atuar como instância especial, é verificar se há no julgamento alguma violação à Lei Federal ou Constituição. Os tribunais superiores só analisam matéria de direito, omitindo-se a reanalisar as provas e o acontecimento em si (matéria de fato). De forma excepcional, os Tribunais Superiores e o STF podem atuar como primeira ou segunda instância, mas apenas nos casos de suas competências originárias previstas na Constituição ou quando um outro tribunal inferior julgar uma causa em primeira instância, para garantir efetividade ao duplo grau de jurisdiçãa $0^{5}$.

Em relação à abrangência territorial, a Justiça Brasileira é dividida em Federal e Estadual, em consonância com o princípio federativo, sendo cada ente federado responsável pela organização e administração da justiça em seu território.

Em nível estadual a justiça é subdividida em comarcas: a comarca é a menor unidade territorial judiciária, podendo conter um ou mais municípios e distritos. Todas as demandas jurídicas que surgirem dentro do espaço territorial da comarca devem ser julgadas, exceto em casos de competências extraordinárias, pelo Juiz de Direito da comarca. Além disso, cada comarca pode contar ainda com uma ou mais varas. As varas são subdivisões temáticas da comarca, assim, se uma comarca possuir uma vara única apenas, será ela competente para julgar todos os tipos de processo. Se houver mais de uma vara, essas repartirão as competências entre si. As divisões mais comuns são: vara

\footnotetext{
${ }^{5}$ Esta atuação não é atípica para o Superior Tribunal Militar que atua, dentro da justiça federal militar, regularmente como órgão recursal de segunda instância.
} 
cível, criminal, da família e sucessões, de menores. Pode haver quantas varas forem necessárias em uma comarca e cada vara é presidida por um juiz de direito. A comarca representa, no estado, a primeira instância de justiça. Além das comarcas, cada estado possui seu Tribunal, que é responsável pela administração da justiça no estado, criação de novas comarcas, extinção de comarcas existentes e etc., bem como por exercer a função de segunda instância (processar e julgar os recursos) e em casos excepcionais de sua competência originária, exercer a função de primeira instância.

No âmbito federal a justiça é organizada primariamente a partir das seções judiciárias, que correspondem a cada um dos estados brasileiros e uma ao Distrito Federal. As seções judiciárias exercem, por meio de juízes monocráticos, a função de primeira instância da justiça federal. Da mesma forma que as comarcas, as seções judiciárias também podem ser subdivididas em varas, que são localizadas uma em cada capital do país e outras em algumas cidades do interior. Para a segunda instância, a justiça federal se organiza por regiões, cada qual com seu Tribunal Regional Federal TRF. As regiões são um agrupamento de seções judiciárias, sendo que: a $1^{\mathrm{a}}$ Região compreende as seções judiciárias do Acre, Amapá, Amazonas, Bahia, Distrito Federal, Goiás, Maranhão, Minas Gerais, Mato Grosso, Pará, Piauí, Rondônia, Roraima e Tocantins e possui sua sede em Brasília; a $2^{a}$ Região compreende as seções judiciárias do Rio de Janeiro e Espírito Santo com sede no Rio de Janeiro; a $3^{\text {a }}$ Região compreende as seções judiciárias de São Paulo e Mato Grosso do Sul com sede em São Paulo; $4^{a}$ Região compreende as seções judiciárias de Paraná, Santa Catarina e Rio Grande do Sul e a sede localiza-se em Porto Alegre; por último, a $5^{\text {a }}$ Região compreende as seções judiciárias de Alagoas, Ceará, Paraíba, Pernambuco, Rio Grande do Norte e Sergipe com a sede em Recife.

A definição das matérias que devem ser julgadas pela justiça federal é realizada pelos artigos 108 e 109 da Constituição, são elas as causas que possuem como parte a União, suas autarquias, as empresas públicas federais, as disputas de direito indígena dentre outras.

A divisão entre justiça comum e especializada é uma separação por matéria. Nossa constituição reconhece que em função de sua relevância e autonomia dentro do campo do direito algumas matérias merecem um sistema judiciário próprio, muitas vezes com tribunais e juízes completamente independentes do sistema de justiça comum. As justiças especializadas são três: Justiça do Trabalho; Justiça Eleitoral e Justiça Militar.

À Justiça do Trabalho compete causas relativas ao Direito Trabalhista, como as referentes às relações de emprego, demissões, greves ou representações sindicais. É uma justiça federal e se separa quase completamente da Justiça Comum por possuir Juízes e Tribunais próprios. Todavia, caso não haja, em uma determinada comarca, uma vara 
do trabalho e aquela não esteja sob a jurisdição de alguma vara do trabalho, o juiz da justiça comum poderá atuar como juiz do trabalho.

A Justiça Militar julga os militares (Soldados, Policiais Militares, Bombeiros Militares e etc.) em crimes militares (previstos no Código Penal Militar) e ações contra atos disciplinares militares. Existe tanto em nível federal quanto estadual, sendo que é facultado aos estados criarem a justiça militar caso julguem necessário. Caso não criem, as causas militares serão julgadas pela justiça comum, levando em conta o Direito Militar.

A Justiça Eleitoral, por sua vez, organiza e administra as eleições, além de julgar causas relativas as eleições e partidos políticos. Da mesma forma que a Justiça do Trabalho, é uma justiça federal, entretanto não é separada completamente da justiça comum, são os juízes de direito estaduais responsáveis por exercerem a jurisdição nas zonas eleitorais. Além disso, a justiça eleitoral é responsável por criar um órgão, predominantemente administrativo, para administrar as eleições, a junta eleitoral. Esta é composta por um juiz eleitoral e de dois a quatro cidadãos, a junta tem duração curta, apenas a necessária para o bom funcionamento das eleições.

Quadro 2 - Organização da Justiça no Brasil

\begin{tabular}{|c|c|c|c|c|c|c|}
\hline & \multicolumn{2}{|l|}{ Comum } & \multicolumn{4}{|l|}{ Especializada } \\
\hline & \multirow{2}{*}{\begin{tabular}{|l} 
Estadual \\
Juiz de \\
Direito \\
(Comarcas)
\end{tabular}} & \multirow{2}{*}{$\begin{array}{l}\text { Federal } \\
\text { Juiz } \\
\text { Federal }\end{array}$} & \multirow{2}{*}{\begin{tabular}{|l} 
Estadual \\
Juiz Militar ou \\
Conselho de Justiça \\
ou Juiz de Direito
\end{tabular}} & \multicolumn{3}{|l|}{ Federal } \\
\hline $\begin{array}{l}1^{\mathrm{a}} \\
\text { Instância }\end{array}$ & & & & $\begin{array}{l}\text { Conselho } \\
\text { de Justiça }\end{array}$ & $\begin{array}{l}\text { Juiz do } \\
\text { Trabalho } \\
\text { (Vara) }\end{array}$ & Juiz Eleitoral \\
\hline $\begin{array}{l}2^{\mathrm{a}} \\
\text { Instância }\end{array}$ & $\begin{array}{l}\text { Tribunal de } \\
\text { Justiça }\end{array}$ & $\begin{array}{l}\text { Tribunal } \\
\text { Regional } \\
\text { Federal }\end{array}$ & Tribunal Militar & $\begin{array}{l}\text { Superior } \\
\text { Tribunal } \\
\text { Militar }\end{array}$ & $\begin{array}{l}\text { Tribunal } \\
\text { Regional do } \\
\text { Trabalho }\end{array}$ & $\begin{array}{l}\text { Tribunal } \\
\text { Regional } \\
\text { Eleitoral }\end{array}$ \\
\hline \multirow[t]{2}{*}{$\begin{array}{l}\text { Instâncias } \\
\text { Especiais }\end{array}$} & \multicolumn{4}{|c|}{ Superior Tribunal de Justiça } & $\begin{array}{l}\text { Tribunal } \\
\text { Superior do } \\
\text { Trabalho }\end{array}$ & $\begin{array}{l}\text { Tribunal } \\
\text { Superior } \\
\text { Eleitoral }\end{array}$ \\
\hline & \multicolumn{6}{|c|}{ Supremo Tribunal Federal } \\
\hline
\end{tabular}

Fonte: 0 autor

Podemos, ao fim, perceber que há um longo caminho percorrido até que 0 acórdão seja proferido. Primeiro deve surgir um conflito sobre um direito (i.e. dúvida sobre a posse de um bem, violação de um direito autoral, dano ao patrimônio, lesão 
corporal e etc.), deve ser formulada uma demanda jurídica e postulada perante um órgão jurisdicional (juiz ou tribunal). A demanda deve ser julgada em primeira instância, para que uma das partes recorra e, por último, o recurso deve ser recebido e julgado em segunda instância.

Como aponta Schritzmeyer (2004) a partir da pesquisa do historiador Keith Thomas, os acórdãos são a "ponta do iceberg" do mundo jurídico. Apenas uma pequena parte (a ponta) é visível, sendo impossível a correta mensuração da base. Se comparado com o volume de processos que ingressam em primeira instância, o número de casos que chegam até a segunda instância é pequeno. Segundo dados do Conselho Nacional de Justiça - CNJ, estima-se que, só em Minas Gerais, no período de 2010, apenas 7,4\% das decisões de primeira instância passíveis de recurso a um tribunal de fato sofreram um recurso (CONSELHO NACIONAL DE JUSTIÇA, 2010, p. 270).

Muito embora diversos casos se perdem, a "ponta do iceberg" não é pequena. No mesmo ano de 2010, o Tribunal de Justiça de Minas Gerais obteve 189.612 novos casos (CONSELHO NACIONAL DE JUSTIÇA, 2010, p. 111), assim, o universo total de casos que podem ser coletados é extremamente grande e exige um recorte bem planejado para não impossibilitar a pesquisa. Ao mesmo tempo, o grande volume de casos permite facilmente trabalhar com amostras com grande N, o que segundo King, Keohane e Verba (1994) facilita alcançar inferências mais precisas. 0 volume grande de acórdãos pode constituir, então, tanto uma vantagem, quanto uma desvantagem para a pesquisa. Os caminhos mais comuns para se chegar a um acórdão estão ilustrados na figura abaixo, sendo que cada hexágono representa um caminho que não leva à produção de um acórdão e, consequentemente, são casos que não podem ser observados a partir de uma pesquisa com acórdãos. Já os losangos representam um processo que chegou com sucesso a um acórdão. 


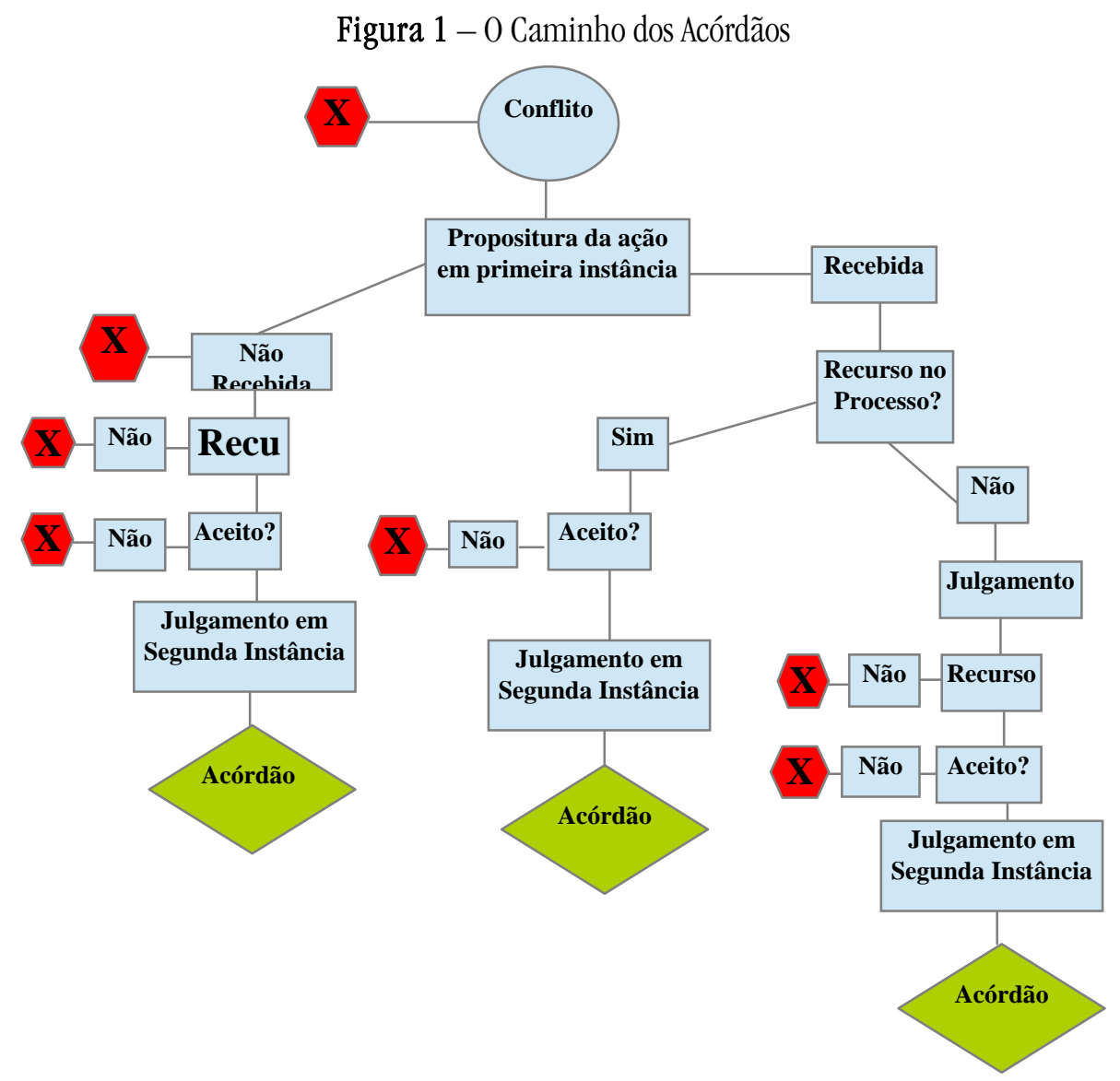

Fonte: 0 autor

Os acórdãos são, então, uma decisão colegiada proferida por um tribunal de segunda instância. 0 acórdão é composto pelos votos de no mínimo três desembargadores, sendo que os votos podem ou não coincidir em suas argumentações e fundamentações. A estrutura dos acórdãos varia, não havendo uma padronização entre os vários tribunais, ponto dificultador para a pesquisa. É necessário, porém, que contenham alguns elementos exigidos por Lei, são eles: a) o relatório, que conterá os nomes das partes, a síntese do pedido e da resposta do réu, bem como o registro das principais ocorrências havidas no andamento do processo; $b$ ) os fundamentos, em que 0 juiz analisará as questões de fato e de direito; c) o dispositivo, em que o juiz resolverá as 
questões, que as partes lhe submeterem (art. 458 do Código de Processo Civil - CPC) (BRASIL, 1973).

Os acórdãos são documentos públicos, podendo ser facilmente acessados por qualquer pessoa, por meio de uma busca por palavras chaves nos repositórios online de jurisprudência dos tribunais (um sistema de busca similar ao do Google). Esses repositórios fornecem acesso ao texto integral das decisões, bem como outras informações sobre o processo. Apenas em casos excepcionais, alguns tribunais, como 0 de São Paulo, optam por não publicar o inteiro teor do acórdão a fim de salvaguardar as partes, ficando disponível apenas o dispositivo. Outros tribunais, como o de Minas, opta por publicar a íntegra do acórdão, mas omitir os nomes das partes. Cada tribunal possui seu próprio sistema de busca e não há uniformização entre eles, nem em relação a forma como o acórdão é disponibilizado: é possível encontrar o texto como parte integrante do próprio site ou como um arquivo de texto para descarregar em seu computador. É importante entender que os repositórios online estão em processo de constante atualização e alteração, o que pode levar a suspensão de acesso a um período temporal inteiro para, por exemplo, revisar o formato do documento disponibilizado. É comum ainda que os sistemas de busca fiquem fora do ar em momentos de muito acesso. É prudente que o/a pesquisador/a entre em contato com os setores responsáveis pela disponibilização dos documentos para se inteirarem sobre os processos de construção do repositório e sobre quais dados estão de fato disponíveis. Particularmente o STJ e o STF foram muito receptivos a todas as demandas realizadas por mim, os funcionários responsáveis responderam rapidamente as perguntas e ainda sugeriram novas formas de se realizar a busca para refinar os resultados. Pesquisas históricas anteriores aos anos 2000 não devem se restringir aos repositórios online, já que os tribunais não digitalizaram e disponibilizaram completamente seu acervo de jurisprudência.

Os acórdãos podem, também, ser encontrados em revistas de jurisprudência, como a Revista dos Tribunais. Essas revistas, apesar de cada vez mais raras tem o mérito de publicar apenas acórdãos que são marcados por alguma especificidade que o faz merecer ser divulgado, desde características atípicas a uma nova forma de se decidir sobre uma determinada matéria. As revistas de jurisprudência são fontes mais confiáveis para a busca de acórdãos antigos, por outro lado, possuem o ponto negativo de não fornecerem um acervo extenso sobre um mesmo tema, nos mesmos moldes fornecidos de busca por palavras chaves no repositório online de um tribunal. Se, por um lado, essa seletividade recorta acórdãos considerados relevantes para 0 mundo jurídico, é necessário ponderar que exclui muitos outros. É prudente levar em consideração que qualquer amostra construída a partir dessas revistas estará, desde sempre, marcada pelo viés da seleção previa do que deve ou não ser publicado. É possível ainda a consulta ao acervo físico que os tribunais mantem mediante requisição. 
Por serem documentos escritos e oficiais do Estado, duas questões devem ser levadas em conta: a da interpretação e a do poder (OLIVEIRA; SILVA, 2005). A questão do poder se dá, pois o discurso que se apresenta nos acórdãos é indireto, filtrado e recontado pelo Estado. Isso ocorre principalmente nos processos criminais em que o próprio relato das testemunhas é filtrado por juízes, promotores e escrivães. Segundo Oliveira e Silva (2005, p. 247) pode-se dizer que "o que há nesses processos é o Estado falando, e todos os discursos do processo estariam mais propriamente sendo proferidos por ele. Expressariam, desse modo, o Estado exercendo o controle da sociedade por meio da produção de uma verdade."

Nos estudos com acórdãos, ainda assim, não há razões para se considerar que 0 Estado que profere os discursos é um sujeito monolítico e com o discurso coerente entre si e com os outros já proferidos. Cada desembargador tem independência para julgar da forma que acreditar ser a melhor, desde que juridicamente fundamentado (arts. 131 do CPC e 155 do CPP). É comum haver dentro de um mesmo tribunal conflitos entre formas de se compreender e julgar um caso e há, também, conflitos entre diferentes tribunais. Mesmo um acórdão não pode ser percebido como um discurso único, coerente e proferido unicamente pelo Estado. Apesar da mediação dos discursos pelos magistrados, não é possível apagar completamente da narrativa os modos como determinadas pessoas vivenciam a realidade, seja essa pessoa os desembargadores, as partes ou ainda uma testemunha. 0 processo e 0 acórdão podem ser compreendidos como uma narrativa, construída pela e na interação dos diversos atores e atrizes que compõem o processo (desembargadores, advogados, partes, testemunhas). A história contada servirá para justificar a forma como o poder foi exercido. Dessa narrativa é difícil apagar completamente o discurso dos outros atores que não o ator estatal. Os limites da decisão são impostos pelas partes e caso o magistrado não os respeite produzirá uma decisão infra, ultra ou extra petita (respectivamente, uma decisão que é inferior ao limites do pedido, que ultrapassa os limites ou, ainda, que decide sobre algo que não foi pedido), isso faz com que seja importante se perguntar sobre quem são os agentes que usam do processo, quais suas intenções e quais estratégias foram utilizadas para limitar ou direcionar a decisão do magistrado. Entretanto, pelo poder do estado de mediar o discurso, é importante ainda perguntar "como os eventos são definidos, quais os eventos são incluídos na narração e quais são excluídos e que princípios governam 0 processo de seleção." (STEINMETZ apud OLIVEIRA; SILVA, 2005, p. 252). As inclusões e exclusões da narrativa e o processo de escolha da melhor resposta jurídica possível importam, pois não são neutros, revelando os valores e crenças dos magistrados (OLIVEIRA; SILVA, 2005; SCHRITZMEYER, 2004).

Em relação à interpretação é preciso levar em conta que a pesquisa, cuja única fonte é constituída pelos acórdãos, não acessa diretamente o acontecimento (0 julgamento ou a própria situação que levou ao julgamento), mas um texto de terceiros 
(os magistrados) que reconta e analisa os fatos. 0 texto jurídico possui algumas particularidades, sendo a primeira a linguagem com que é escrito, o juridiquês, de difícil compreensão para aqueles sem formação jurídica. 0 acórdão é populado por diversos termos técnicos, expressões latinas e rebuscadas, que objetivam garantir ao texto uma impessoalidade, neutralidade e universalidade (BOURDIEU, 1990). Tentativa essa jamais sucedida, a complexa rede de conflitos e interações sociais que formam os sujeitos do processo e o próprio processo, persiste no texto. Tal persistência é mostrada por Schritzmeyer (2004) ao analisar os cuidados e bajulações que os desembargadores fazem quando se referem ao juiz de primeira instância que proferiu a sentença original, sempre com muitos elogios (douta sentença, ilustre julgado e outros), mesmo quando discorda e reformará a sentença. Dessa forma, a partir da:

[...] análise das narrativas dos processos judiciais, pode-se buscar aquilo que é transmitido com a ocorrência de determinados comportamentos e com 0 discurso sobre esses comportamentos, ou seja, pode-se apreender a lógica que informa tais comportamentos e discursos empreendidos (OLIVEIRA; SILVA, 2005, p. 257).

Os acórdãos possuem ainda uma característica especial, que fazem com que mereçam ser analisados: são instrumentos importantes para fundar e consolidar paradigmas jurídicos. Estes se tornam jurisprudência e podem ser referenciados em outros acórdãos, sentenças, petições de advogados e até mesmos em livros e artigos jurídicos como fundamento jurídico de um argumento. Encontrar um acórdão que vá na direção da argumentação desenvolvida é um ponto importante no trabalho de um advogado. Aquele não apenas indica, para o juiz, a possibilidade de julgar da forma desejada, mas, também, indica a chance do tribunal, em sede de recurso, reformar a decisão caso não decida da forma requerida. É a força padronizadora do acórdão. As sentenças de primeiro grau podem igualmente fundar/consolidar paradigmas, bem como ser referenciadas em acórdãos e na literatura jurídica, todavia, isso é menos frequente já que são proferidas por juízes de primeiro grau (o mais baixo grau na hierarquia) e não recebem a mesma publicidade que os acórdãos. As especifidades da linguagem do acórdão, somadas ao poder de serem referenciados, fornecem o último dos pontos que favorecem uma pesquisa com acórdãos, mais especificamente uma análise detalhada dos seus textos, a produção de retratos padronizados e padronizadores:

Não costumam ser numerosas as referências a respeito de réus e vítimas nesses documentos [acórdãos]. Mas, justamente pelo duplo esforço de síntese e embasamento que sua redação exige, o juiz relator costuma destacar no texto do acórdão algumas características que compõem um estereótipo dos envolvidos. E como tratando-se de jurisprudência, tais características ganham a força de clichês a serem buscados em novos casos, 
é importante uma análise cuidadosa desses "retratos padronizados e padronizadores" (SCHRITZMEYER, 2004, p. 125).

Esses retratos padronizados e padronizadores são especialmente ricos para as pesquisas em Ciências Sociais, possibilitando ao pesquisador(a) compreender como a realidade tem sido construída na prática jurídica e a identificação dos jogos de poder presentes nas caracterizações dos sujeitos e dos casos.

\section{ALGUNS EXEMPLOS DE PESQUISAS}

Os acórdãos podem ser utilizados para as mais variadas pesquisas, seja na antropologia, sociologia ou ciência política. Algumas pesquisas serão apresentadas para exemplificar alguns desenhos de pesquisa, tamanhos de amostra, técnicas, objetivos e dados possíveis de serem utilizados e coletados em uma pesquisa com acórdãos.

1) Rosa Oliveira (2009), em Isso é contra a natureza? Decisões e discursos sobre conjugalidade homoerótica em tribunais brasileiros, realizou uma análise de discursos de tribunais brasileiros sobre as conjugalidades homoeróticas. Para isso a pesquisadora construiu uma amostra de 187 acórdãos, coletados nos repositórios online dos tribunais do Rio de Janeiro, Rio Grande do Sul, São Paulo e Minas Gerais e nas revistas Forense e Revista dos Tribunais, os acórdãos coletados são referentes ao período de janeiro de 1989 a junho de 2008. A metodologia da pesquisa é majoritariamente qualitativa e utiliza outras técnicas complementares como a entrevista com desembargadores que proferiram os acórdãos para adquirir outros dados que permitam qualificar a análise. Conclui a autora que os tribunais têm sido mais favoráveis do que contrários ao reconhecimento de efeitos jurídicos aos casais de pessoas do mesmo sexo (45\% de respostas favoráveis, $7 \%$ respostas parcialmente favoráveis e $48 \%$ de respostas desfavoráveis). Percebe ainda que não se pode afirmar categoricamente que as posições desfavoráveis do ponto de vista técnico são homofóbicas, pois como as entrevistas permitiram observar "o pressuposto positivista de apego à letra da lei fala tão alto quanto convicções morais ou religiosas." (OLIVEIRA, 2009, p. 232). Dessa maneira, a negativa do reconhecimento jurídico pode acontecer mesmo quando as convicções pessoais do desembargador são favoráveis em razão de ausência de lei específica que regulamente a união.

2) Ana Lúcia Pastore Schritzmeyer, em seu livro Sortilégio de Saberes: curandeiros e juizes nos tribunais brasileiros (1900-1990) procura compreender "como a lógica das leis penais, consideradas traduções, 'modernas,' racionais e científicas dos princípios reguladores da vida em sociedade, é posta em prática diante da lógica das leis mágicas, consideradas traduções 'primitivas' e místicas desses mesmos princípios reguladores" (SCHRITZMEYER, 2004, p. 84). Para isso, Schritzmeyer constrói uma amostra com 233 acórdãos sobre curandeirismo, charlatanismo e exploração da 
credulidade pública referentes ao período de 1900 a 1990, coletados das Revista dos Tribunais e Revista Forense. Para a parte quantitativa, toda a amostra foi analisada coletando dados como tipo de recurso, quem o interpôs e contra quem, qual tribunal, agentes mencionados no texto do acórdão e qualificativos usados para referir-se a esses agentes (como espertalhões, farsantes, ignorantes, incultos, doentes, ou outros), data, parecer do ministério público, revista onde foi encontrado e outros dados. Para a parte qualitativa da pesquisa, Schritzmeyer selecionou os casos mais paradigmáticos dentre aquela amostra, por meio de um controle cruzado, ou seja, o acórdão deveria estar citado simultaneamente nas duas revistas jurídicas consultadas pela autora e, também, em pelo menos três das quatro fontes complementares de pesquisa (catálogos de bibliotecas, códigos penais comentados consultados, outros acórdãos da amostra ou índices-verbetes das Revistas dos Tribunais ou da Revista Forense). A partir desse procedimento selecionou 7 acórdãos, os quais considerou mais representativos e os submeteu a uma análise mais aprofundada. A análise mostrou que os pressupostos positivistas, evolucionistas e darwinistas sobre as sociedades, aparentemente mortos, continuavam vivos nas análises e sentenças dos juízes ao julgarem sobre curas mágicoreligiosas (SCHRITZMEYER, 2004, p. 173-174).

3) A cientista política Marlise Matos (2011), em sua pesquisa recente, buscou analisar a qualidade do acesso ao direito e à justiça brasileiros na perspectiva de gênero, sexualidade, raça e etnia. A pesquisa coletou 2874 acórdãos nas justiças especializadas (trabalho, militar e eleitoral) e criminal referente aos estados de Minas Gerais, São Paulo, Rio Grande do Sul, Distrito Federal e Ceará. 0 recorte temporal foi o ano de 2009 e a coleta foi realizada através de busca, nos repositórios online dos tribunais, de diversas palavras-chaves que indicariam um caso de discriminação racial, homofóbica ou de gênero. Os acórdãos foram filtrados para apenas ingressarem na amostra caso estivesse presente alguma forma de discriminação racial, homofóbica ou de gênero, não bastando que a palavra buscada (por exemplo homossexual) constasse no texto do acórdão. Alguns dos dados coletados pela pesquisa foram: tribunal de origem, órgão julgador, data do julgamento, data do início do processo, tipo de recurso, nome do relator, sexo do relator e seu voto, se houve ou não absolvição, tipo de pena, tempo da pena, se há indenização e caso haja o valor da indenização também foi coletado. 0 relatório parcial da pesquisa publicado no formato de livro dá conta principalmente da análise quantitativa dos dados e revela, dentre outras coisas, dados impressionantes como o conservadorismo da justiça criminal mineira que julgou 69,8\% dos acórdãos analisados de forma desfavorável, enquanto São Paulo, frente ao mesmo tipo de casos, julgou apenas 21,9\% de forma desfavorável (MATOS, 2011, p. 108). 


\section{APONTAMENTOS FINAIS}

0 percurso desenvolvido no presente trabalho oferece algumas pistas para cientistas sociais que buscam desbravar o mundo jurídico e para juristas que desejam refinar suas pesquisas com métodos das ciências sociais. Procurei menos apontar 0 caminho correto a ser seguido, meu foco foi tentar apontar para a pluralidade de possibilidades metodológicas, bem como os ganhos e perdas que cada escolha provocará. Para isso, apresentei a metodologia dos estudos de caso e de casos cruzados na primeira seção do texto e ao abordar o sistema jurídico e a formação do acórdão, tentei dar pistas de como os aspectos metodológicos afetariam a pesquisa. Um bom exemplo pode ser tomado a partir da observação das pesquisas de Matos (2011) e Schritzmeyer (2004). Matos (2011) fez uma escolha metodológica difícil, apesar de focar sua pesquisa em apenas um ano, optou por abordar muitos temas diferentes e usar muitas palavras chaves. Essa escolha levou a coleta de um volume muito grande de casos, que surpreendeu a pesquisadora.

Se por um lado isso possibilitou a produção de uma comparação estatística entre os tribunais, Matos pagou o preço de ter que repensar sua metodologia ao longo da pesquisa, "porque diante do volume [de dados] já identificado não será possível processar no caso destes tribunais todo o universo" (MATOS, 2011, p. 99). Schritzmeyer (2004) também coletou um número grande de casos em sua pesquisa, mas ideou uma estratégia para selecionar aqueles mais relevantes para a análise detalhada do texto. Uma estratégia similar será necessária para Matos (2011) se deseja de fato realizar a parte qualitativa que anuncia em seu relatório como a fase seguinte da pesquisa.

A metodologia apresentada aqui, fortemente influenciada por Gerring (2007), tem a vantagem de ser bastante flexível. Os acórdãos podem ocupar diferentes posições na pesquisa, dependendo do nível da análise pretendida. Uma pesquisa pode querer comparar tribunais, tomando-os como casos e os acórdãos como observações que compõem o caso. Outra pesquisa pode ter outro nível de observação e analisar um único tribunal, comparando os acórdãos ao longo do tempo, nessa hipótese cada acórdão constituiria um caso independente. É possível se aplicar até mesmo a pesquisas que utilizam um único acórdão como caso, comparando, por exemplo, os votos presentes dentro do acórdão. A metodologia pode ainda servir a pesquisas qualitativas, quantitativas ou àquelas que misturem ambas para investigar diversos assuntos como direito à saúde, direitos das pessoas homossexuais ou ainda os conflitos de terra existentes no Brasil. Tentei demonstrar a flexibilidade do uso dos acórdãos com os exemplos concretos de pesquisa.

É preciso reconhecer que existe uma série de outras metodologias que poderiam ser utilizadas para se analisar os acórdãos. Como Brady e Collier (2004) argumentaram, é possível combinar o pluralismo metodológico com o rigor analítico, assim, técnicas 
qualitativas como a da análise do discurso e da análise de conteúdo podem ser conjugadas com a metodologia apresentada aqui para uma melhor análise dos textos dos acórdãos. Uma apresentação adequada dessas outras metodologias faria necessário um outro texto ${ }^{6}$. Mesmo para aquelas pesquisas que não se beneficiem diretamente da metodologia apresentada, podem se beneficiar das considerações realizadas na segunda seção sobre como encontrar um acórdão e ainda sobre a dinâmica da formação do acórdão, que leva à configuração de um texto bem específico atravessado por inúmeras vozes e relações de poder.

Tanto o Direito quanto as Ciências Sociais podem ser utilizadas como instrumento de dominação (CASTILHO, 2012). A agenda de pesquisa que se pretende adensar aqui, no entanto, tem uma tarefa árdua de contribuir com a promoção da justiça, de revelar desigualdades, vicissitudes e relações de poder que atravessam 0 Direito e que muitas vezes correm o risco de ser demasiadamente simplificadas, até mesmo ignoradas ou silenciadas pela prática jurídica. A pesquisa com acórdãos pode fomentar a criação de novas políticas administrativas ou judiciais para ampliar 0 acesso e o reconhecimento de Direitos, como é o caso da pesquisa de Matos (2011) que aponta para o tradicionalismo do Tribunal de Justiça de Minas Gerais e indica que se desejamos um Brasil menos opressivo devemos repensar a forma como esse tribunal lida com as demandas de grupos historicamente oprimidos.

\section{REFERÊNCIAS}

AVRITZER, Leonardo et al. Para uma nova cartografia da justiça no Brasil. Belo Horizonte: Faculdade de Filosofia e Ciências Humanas, 2010.

BARTELS, Larry M. Some unfulfilled promises of quantitative imperialism. In: BRADY, Henry; COLLIER, David (Org.). Rethinking social inquiry: diverse tools, shared standards. Lanham: Rowman \& Littlefield s, 2004. p. 69-74.

BAUER, Martin W. Análise de conteúdo clássica: uma revisão. In: BAUER, Martin W.; GASKELL, G. (Org.) Pesquisa qualitativa com texto, imagem e som: um manual prático. Petrópolis: Vozes, 2003. p.189-217.

\footnotetext{
${ }^{6}$ Machado (2012) faz uma boa apresentação da análise do discurso e atenta à pluralidade de correntes dessa. A corrente desenvolvida por essa autora, com forte influência de Pêcheux e Charaudeau, pode trazer boas contribuições à análise dos acórdãos. Um panorama geral da Análise de Conteúdo pode ser encontrado em Bauer (2003), especialmente útil por conseguir conjugar uma análise quantitativa e qualitativa de aspectos do texto.
} 
BOURDIEU, Pierre. A força do Direito: elementos para uma sociologia do campo jurídico. In: BOURDIEU, Pierre. O poder simbólico. São Paulo: Difel, 1990.

BRADY, Henry; COLLIER, David (Org.). Rethinking social inquiry: diverse tools, shared standards. Lanham: Rowman \& Littlefield Publishers, 2004.

BRASIL. Constituição. Constituição da República Federativa do Brasil. Brasília: Senado, 1988.

BRASIL. Lei n. 5.869, de 11 de janeiro de 1973. Institui o Código de Processo Civil. Diusponível em: <http://www.planalto.gov.br/ccivil_03/leis/15869.htm>. Acesso em: 15 out. 2012.

BRASIL. Decreto Lei $n^{\circ} 3.689$, de 3 de outubro de 1941. Código de Processo Penal. Disponível em: < http://www.planalto.gov.br/ccivil_03/decretolei/del3689compilado.htm>. Acesso em: 15 out. 2012.

CASTILHO, Ela Wiecko V. Introdução. In: LIMA, Roberto Kant de. Antropologia jurídica. In: LIMA, Antonio Carlos de Souza (Org.) Antropologia e direito: temas antropológicos para estudos jurídicos. Rio de Janeiro: Associação Brasileira de Antropologia, 2012.

CONSELHO NACIONAL DE JUSTIÇA. Justiça em números 2010: Justiça Estadual. Brasília, 2010.

GERRING, John. Case study research: principles and practices. Cambridge: Cambridge University Press, 2007.

KING, Gary; KEOHANE, Robert; VERBA, Sidney. Designing social inquiry: scientific inference in qualitative research. New Jersey: Princeton University Press, 1994.

LIMA, Roberto Kant de. Antropologia jurídica. In: LIMA, Antonio Carlos de Souza (Org.). Antropologia e Direito: temas antropológicos para estudos jurídicos. Rio de Janeiro, Brasília: Contra Capa, LACED, Associação Brasileira de Antropologia, 2012.

MACHAD0, Ida Lúcia. Algumas reflexões sobre elementos de base e estratégias da análise do discurso. Revista Estudos Linguísticos, Belo Horizonte, v. 20, n. 1, p. 187-207, jan.jun. 2012.

MATOS, Marlise. Acesso ao Direito e à justiça brasileiros na perspectiva de gênero/sexualidade, raça/etnia: entre o estado e a comunidade. Belo Horizonte: Faculdade de Filosofia e Ciências Humanas, 2011.

NOBRE, Marcos. Apontamentos sobre a pesquisa em direito no Brasil. Cadernos Direito GV, São Paulo, n. 1, set. 2004.

OLIVEIRA, Fabiana Luci de; SILVA, Virgínia Ferreira da. Processos judiciais como fonte de dados: poder e interpretação. Sociologias, Porto Alegre, ano 7, n. 13, p. 244-259, jan./jun. 2005. 
OLIVEIRA, Rosa Maria Rodrigues de. Isto é contra a natureza? Decisões e discursos sobre conjugalidade homoeróticas em tribunais brasileiros. 2009. 256 f. Tese (Doutorado em Ciências Humanas) - Universidade Federal de Santa Catarina, Florianópolis, 2009.

SCHRITZMEYER, Ana Lúcia Pastore. Sortilégio de saberes: curandeiros e juízes nos tribunais brasileiros (1900-1990). São Paulo: IBCCRIM, 2004.

SCHRITZMEYER, Ana Lúcia Pastore. Etnografia dissonante dos tribunais do júri. Tempo Social, São Paulo, v. 19, n. 2, p. 111-129, 2007. 